\title{
Commuter interdependence - A CIF framework
}

\author{
Created by: Bhuvanachithra Chidambaram ${ }^{1}$ \\ 1, Research Associate, TU Dortmund University, Germany; bhuvigna@gmail.com
}

Version received: 5 June 2020

check for updates

The comprehensive research framework is divided into two phases, namely assessment and abatement, each of which involves a method that has been developed on the basis of an analytical framework. The vehicle emission estimation method, in the assessment phase, is built on the basis of the 'Institution of Sustainability' (IOS) framework to assess vehicle emission levels and identify all potential traffic-related sources influencing such emissions. Field experiments are designed, in the abatement phase, on the basis of the 'Institutions and Development' (IAD) framework to analyse the 'near-to-real' commuter interdependence, with respect to demand-based, non-technical measures in the experiment arrangement.

\section{Combined Concept of IoS and IAD}

The Comprehensive Integrated Frameowrk $(\mathrm{CIF})^{[\underline{1}]}$ concept involves three main aspects: on-road vehicle emissions, commuter behaviour, and demand-based traffic strategies. The concept relies on two analytical frameworks, namely IOS and IAD, which, taken together, can also be termed as the combined concept for CIF. First, the concept for assessing on-road traffic-induced vehicle emissions has been developed on the basis of the loS framework (Hagedorn 2005) ${ }^{[2]}$, which highlights the link between 'social transaction and actor interdependence'. Second, the concept for analysing demand-based traffic strategies has been devised on the basis of the IAD framework (Ostrom 1998) ${ }^{[\underline{3}]}$, which emphasizes the importance of 'institutional analysis of demand-based traffic strategies'.

The combined concept highlights the nexus between transaction interdependence and institution (Figure 1). According to loS, the interplay between the properties of transaction and actors causes interdependence, which in turn becomes the core element for institutional design. The framework denotes that the properties of social or natural related transactions mediated by technical or ecological system cause interdependence between actors. Interdependence is the situation in which the actors are mutually dependent on each other actions and this situation in turn motivates the actors to interact with each other that may lead to social dilemma problems. Such characteristics of interdependence form the main basis for designing institutions (Paavola and Adger 2005) ${ }^{[4]}$. The application of loS in transportation context is explained with a sample case.

Figurel Linking loS ans IAD in transportation context

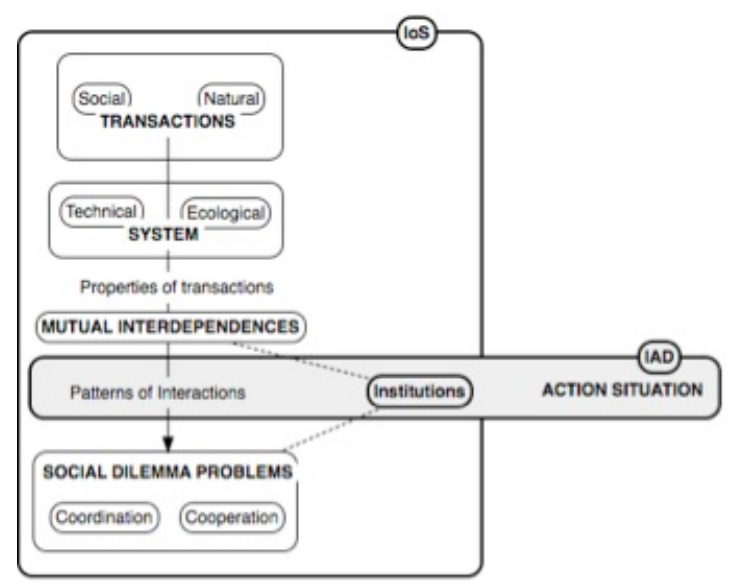




\section{Interdependence, Transaction and Institutions in transportation context}

Figure 2 presents a combined concept of the IOS and IAD involving three main aspects: transactions, interdependence, and institutions. The transaction-interdependence cycle of the loS framework provides a conceptual road map for analysing the social transaction (i.e., average VKT) in the research framework. As such transactions have increased, the properties of the physical aspects (i.e., road capacity and vehicle performance) are affected, which result in negative impacts (i.e., traffic congestion and subsequent vehicle emissions). During this stage, the commuters intentionally or unintentionally interact and a state of mutual interdependence emerges on their varied travel choices. This has necessitated the research framework to include the institutional analysis in which the concepts are based on the IAD framework. The IAD framework set guidelines to analyse demand-based strategies from the behavioural patterns of interactions. This has helped the research to provide policy improvements concerning the emission reduction strategies in the on-road traffic pollution abatement process.

Figure 2: CIF to analyse vehicle emissions and traffic congestion

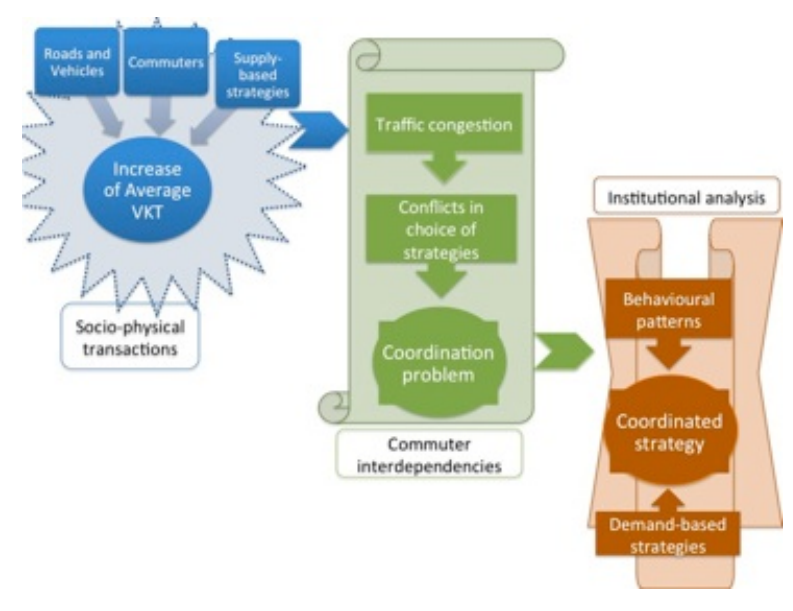

\section{Application of CIF}

The application of CIF in transportation context is explained with a sample case:

Let's assume commuters travelling from one place to other, representing the process of social transactions. The properties of these transactions include the vehicle demand characteristics such as traffic flow, time, speed and operating cost. These properties when mediated by the infrastructural/technical system such as roads and vehicles may cause mutual interdependence among commuters where the problem of mode choice, route choice and travel time choice could arise. This is because the infrastructural/technical system is subjected to limited capacity over the time period (i.e. designed road capacity). Hence commuters are bound to state of mutual interdependences, where the choice of one commuter affect or depends on the choice of other commuters. This form of mutual interdependence may be severe during traffic congestion situation, where more number of commuters tend to cause more interdependences leading to more conflicts in their choice of strategies. Hence, addressing the mutual interdependence among the commuters should form the primary reason for designing transport institutions. For instance, the supply and demand based traffic measures could be designed and implemented in combinations such a way that commuters have always alternate options (i.e. alternate route/ alternate travel mode/ alternate travel time) to travel. Additionally, this could have positive impacts in reducing the vehicle emissions. 


\section{Encyclopedia}

\section{References}

1. Chidambaram, B.. Vehicle Emission Reduction: An Experimental Approach for Analysing Sustainable Traffic Strategies: ; Shakers: Germany, 2016; pp. 37.

2. Konrad Hagedorn; Particular requirements for institutional analysis in nature-related sectors. European Review of Agricultural Economics 2008, 35, 357-384, 10.1093/erae/jbn019.

3. Elinor Ostrom; Background on the Institutional Analysis and Development Framework. Policy Studies Journal 2011, 39, 7-27, 10.1111/j.1541-0072.2010.00394.x.

4. Paavola, J. and Adger, W.; Institutional ecological economics. Ecological Economics 2005, 53 (3), $353-368$.

\section{Keywords}

emission; congestion; institution; interdependence; transaction; IoS; IAD; commuters 